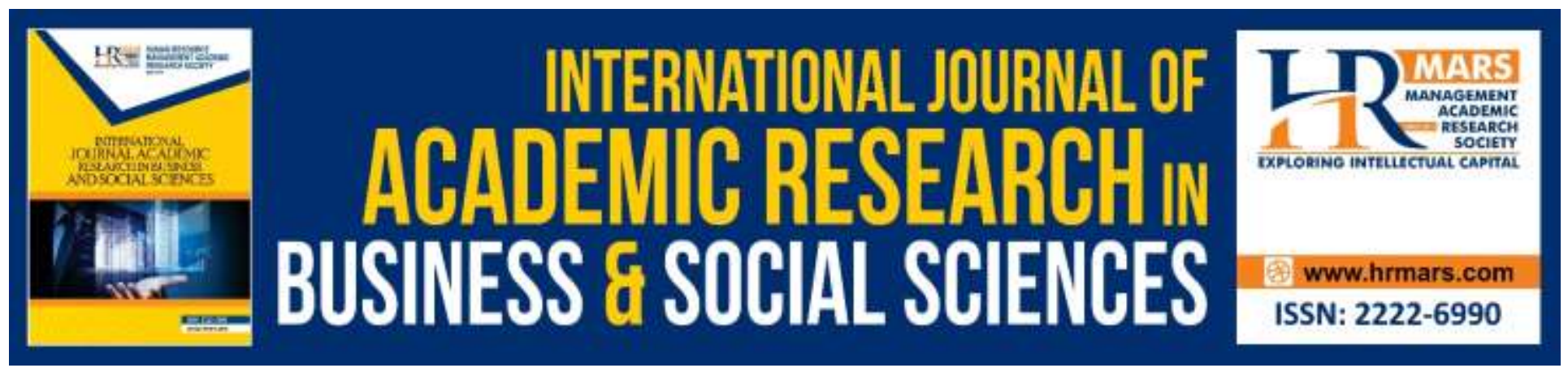

\title{
Human Factors Determinants of Licensed Aircraft Engineers That Influenced Organizational Safety Performance
}

Zaiful Hasmi Hashim, Beni Widarman Yus Kelana, llham Sentosa, Mohd
Khir Harun, Rafidah Othman, Theresa C.F. Ho, Poh-Chuin Teo

To Link this Article: http://dx.doi.org/10.6007/IJARBSS/v10-i5/7203

DOI:10.6007/IJARBSS/v10-i5/7203

Received: 21 March 2020, Revised: 25 April 2020, Accepted: 30 April 2020

Published Online: 15 May 2020

In-Text Citation: (Hashim et al., 2020)

To Cite this Article: Hashim, Z. H., Kelana, B. W. Y., Sentosa, I., Harun, M. K., Othman, R., Ho, T. C. F., \& Teo, P.-C. (2020). Human Factors Determinants of Licensed Aircraft Engineers That Influenced Organizational Safety Performance. International Journal of Academic Research in Business and Social Sciences, 10(5), 337-348.

Copyright: (C) 2020 The Author(s)

Published by Human Resource Management Academic Research Society (www.hrmars.com)

This article is published under the Creative Commons Attribution (CC BY 4.0) license. Anyone may reproduce, distribute, translate and create derivative works of this article (for both commercial and non-commercial purposes), subject to full attribution to the original publication and authors. The full terms of this license may be seen

at: http://creativecommons.org/licences/by/4.0/legalcode

Vol. 10, No. 5, 2020, Pg. 337 - 348

http://hrmars.com/index.php/pages/detail/IJARBSS

JOURNAL HOMEPAGE

Full Terms \& Conditions of access and use can be found at

http://hrmars.com/index.php/pages/detail/publication-ethics 


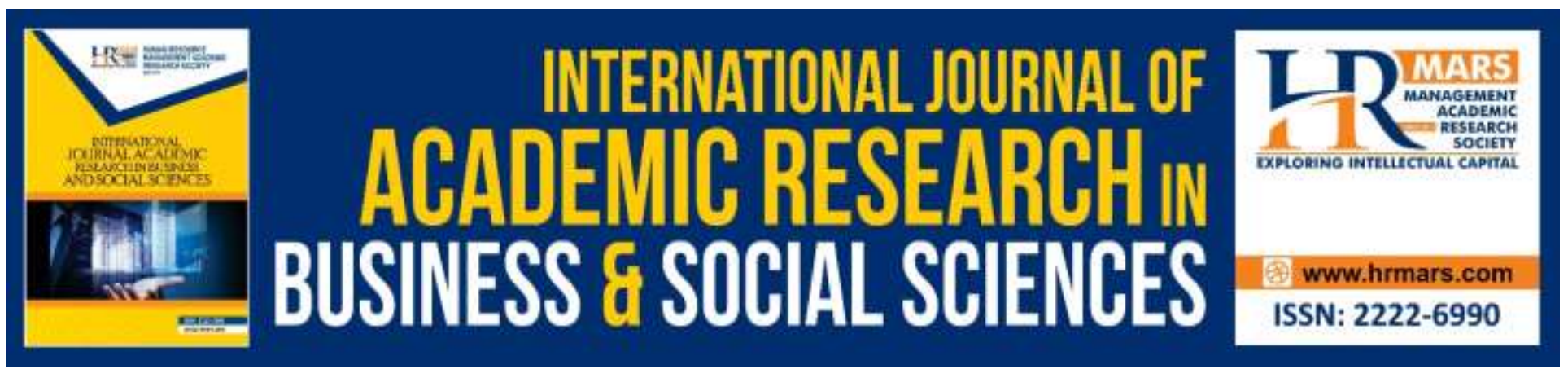

\title{
Human Factors Determinants of Licensed Aircraft Engineers That Influenced Organizational Safety Performance
}

\author{
aZaiful Hasmi Hashim, aBeni Widarman Yus Kelana, bllham \\ Sentosa, 'Mohd Khir Harun, a Rafidah Othman, ${ }^{\text {aTheresa C.F. }}$ \\ Ho, aPoh-Chuin Teo \\ ${ }^{a}$ Azman Hashim International Business School (AHIBS), Universiti Teknologi Malaysia, \\ ${ }^{b}$ Business School, Universiti Kuala Lumpur, 'Malaysian Institute of Aviation Technology, \\ Universiti Kuala Lumpur
}

\begin{abstract}
The aim of this study is to discuss the relationship between human determinant factors which includes attitudes, subjective norms and perceived behavioral control for licensed aircraft engineers in an aircraft maintenance process. This is important as the aircraft maintenance process affects the safety performance for aircraft operations. Licensed aircraft engineers are the individual that certifies the maintenance release for all aircraft maintenance process that is a legal document and form part of the certificate of airworthiness. Theory of Planned Behavior (TPB) will play a significant role as the underpinning theory on the proposed model of the safety performance. It is needed as per the regulations to ensure that the aircraft is maintained accordingly and all systems are serviceable thus ensuring that the aircraft is fit for the intended flight. There are research gaps identified as per the literature review, as not many studies on aviation safety centered on licensed aircraft engineers. Emphasis are also given more on flight operations as compared to aircraft maintenance when it comes to aviation safety studies. As such this study is aimed at fulfilling those gaps and would contribute towards enhancing aviation safety.
\end{abstract}

Keywords: Aircraft Maintenance Process, Licensed Aircraft Engineers, Safety Performance, Maintenance Release, Airworthiness, Human Factors.

\section{Introduction}

The aviation industry has been plagued by safety issues as plane crashes has jumped sharply in 2018, according to a Dutch aviation consulting firm to 70 and the Aviation Safety Network as 500 more people died compared to 2017. This was largely due to accidents related to aircraft maintenance process. Flyjamaica Flight 256 a Boeing 757 suffered a technical problem being the hydraulic system fault which resulted in control problems. The aircraft took off from Guyana bound for Toronto Canada 
suffered hydraulic problem which caused the pilot to abort the climb and return to base. The aircraft suffered severe damage due runway overran and resulted in passenger death. (Harro, 2019). A total of 24 crashes happened in 2016, and in 2017, a total of 12 air crashes happened whereas in 2018 a total of 15 crashes were recorded (Aviation Safety report, 2019). Aircraft maintenance process accounts for 26 percent of the crashes in 2016, about 28\% in 2017 and 30\% in 2018 (Harro, 2019). As such safety performance of aircraft maintenance organizations and its personnel that results in aircraft operational safety need to be examined (Keller, 2020).

\section{Objective of study}

This study is written

1. To mitigate the effects of aircraft maintenance process safety performance of its organizations and personnel and provide a safer aviation operation.

2. To concentrate on Licensed aircraft engineer's profession and the individual human factors determinants towards enhancing safety performance in the aircraft maintenance process. By enhancing the safety performance not only more people would be enticed to fly also it contributes to the well-being of the industry by improving the bottom line in terms of higher revenue and optimized cost of the aviation industry and thus assist in the development of the aviation industry (Keller, 2020). Focusing on the human factors that affects the individual licensed aircraft engineer, we are able to assess the overall impact on the organizational safety performance in the aircraft maintenance organizations.

This is important as maintenance of aircraft is an extremely important process to ensure the safety of aircraft operation (McDonald et al., 2000). Even though it is an important element in ensuring aircraft airworthiness, aircraft maintenance process has not been given the attention it deserves as a research subject, to ensure safety in aviation (Atak, 2011).

Licensed Aircraft Engineers (LAES) are engineers to whom an organization has entrusted the role of certifying for the correct state of systems maintained on an aircraft, and he or she will affect their certification on the maintenance release(MR) once they are sure that the systems are fully serviceable and the aircraft is mission capable (Harro, 2019). The MR is a legal document attesting the fitness of the aircraft to perform its intended functions following maintenance and inspections whilst assigning full responsibility for the maintenance and inspections performed through the MR by the issuing certification of the licensed aircraft engineer (AEI, 2020).

As such the importance of the licensed aircraft engineer as a critical function of the aircraft maintenance process and the overall responsibility to ensure the safety of the aircraft prior to the aircraft being flown by the pilot (Harro, 2019). Safety is a socially constructed and not a given condition. It is also a relative organizational value factor dependent upon the safety practices of the organization (Richter and Koch, 2004). Aviation safety is thus an important factor in aviation operations and aircraft maintenance process plays a key role in ensuring its safe operating environment (Keller, 2020).

Human factors for licensed aircraft engineer is truly important as it is an area that influences how best the licensed aircraft engineer perform their professional role in terms of their aircraft 
INTERNATIONAL JOURNAL OF ACADEMIC RESEARCH IN BUSINESS AND SOCIAL SCIENCES

Vol. 10, No. 5, May, 2020, E-ISSN: 2222-6990 @ 2020 HRMARS

maintenance duties as it will ultimately affect the safety and the quality of the work performed and in turn will affect the airworthiness of the aircraft (Harro, 2019).

3. The present study also will benefit human factors in aviation maintenance as human factor is one of the safety barriers which is used in order to prevent accidents, serious incidents or incidents of aircraft (Virovac, Donitrovic, and Baijanac, 2016). Furthermore, safety intentions which include personal commitment to behave in certain ways is needed in order to achieve a desirable outcome, in this case the outcome is safety (Geller, 2008).

\section{Underpinning Theory and Conceptual Modelling}

Development of aircraft maintenance safety management, as an example of maintenance error accident, a B737-200 Aloha Airlines Flight 243 was on a scheduled flight between Hilo and Honolulu suffered an explosive decompression whilst in flight due to metal fatigue and improper inspection by the maintenance crew. A fuselage examination was scheduled during the night, this made it more difficult to carry out an adequate inspection of the aircraft's outer skin and the cracked skin was not spotted as this was the cause of the skin failure (NTSB, 1989).

Why are human conditions, such as fatigue, complacency and stress are so important in aircraft maintenance? These conditions along with many others, are called human factors. Human factors directly cause or contribute to many aviation accidents. It is universally accepted that $80 \%$ of maintenance errors involved human factors. If they are not detected, they can cause events, worker injuries, wasted time and even accidents (FAA, 2019).

The Aloha Airline Accident started the development of the aircraft maintenance resource management program (Zrst, 2019). As part of the study of safety performance in aircraft maintenance the following human factor models are utilized such as the "Dirty Dozen", it refers to twelve of the most common human error pre-conditions (Dupont, 2009). Gordon Dupont developed these concepts, whilst working for Transport Canada. These concepts were adopted as the main elements of human errors analysis and as part of human factors training in the maintenance resource management program (Skybrary, 2017).

The adoption of safety performance in the aviation industry particularly in aircraft maintenance process has led to various adaptations by different stakeholders in the form of safety management system (SMS) for the aviation organizations and state safety policy (SSP)for the contracting state, was triggered by the Aloha airlines flight 243 incident on April 28, 1988 (Human Factors Training, Zrst, 2018).

The former referenced to the organizations whereas the latter to the regulator (SMM9859 Ed.4, 2019). The individual in the organization whether an authorized signatory such as the licensed aircraft engineer or the nominated post holder which represent the management of the aircraft maintenance organization or even the support staff adopted the safety intention objectives (Human Factors Training, Zrst, 2018). 
As such defining Safety Performance in the aircraft maintenance process is a complex proposition as it involves different stakeholders at different levels. Aviation Industry is a highly regulated industry and international civil aviation organization (ICAO) which has been founded in 1944, has been entrusted to regulate and provide the oversight on the international civil aviation industry. The international civil aviation organization (ICAO) is a united nation specialized agency, established by the contracting states to manage the administration and governance of the convention on international civil aviation which is also referred as the Chicago convention.

International civil aviation organization (ICAO) core mandate then as today, was to help countries to achieve the highest possible degree of uniformity in civil aviation regulations, standards, procedures and organization. In order to regulate the international civil aviation, the international civil aviation organization (ICAO) formulates the convention annexes which serves as the law of the land for international civil aviation. (ICAO, 2019).

Human related accidents in aviation operational context results in high economic impact in terms of loss of lives, loss of financial resources and loss of reputation. Today as technology advances in the industry, more observation of human factor related accidents are carried out and being investigated. However, causation models showed that organizational factors influenced the individual safety performance as the case for Turkish pilots (Uryan, 2010). This can also reflect on the same accident causation models targeted at licensed aircraft engineers in contracting nations. To date the observation on these studies has not been explored as such the need to explore and formulate the causation model and its risk management modelling.

As for the training today part of the training to be a licensed aircraft engineer one has to complete multiple modules, from basic aerodynamics to complex aircraft systems and also includes modules on human factors and air legislation. On top of that the candidates are evaluated using both theoretical and practical assessments system by qualified examiners and assessors (AN1101, 2014). Licensed aircraft engineers are also needed to attend a continuation training on the subjects of human factors and air legislation once every twenty-four months as part of their continuation training programme (N6501, 2018).

To inculcate organizational safety performance, we need to look at not only the organizational culture but also the professional and national culture of the individual and organization (SCAA, 2018). By inculcating the correct safety culture, we can then enhance the safety intentions towards a positive organizational safety performance. Aviation organizations must adhere to high safety standards due to its high risk nature to mitigate human factor related accidents by forming and establishing cultures that support safety performance in the organization as it can positively affect the individual behavior at the workplace (Mearns, Flin, Gordon and Fleming, 2001).

However, several studies denote on the personnel work behaviors as it relates to the organizational safety performance and have traced the individual professional, organizational and national cultures that affects human factors elements in the individual work behaviors. It also points to the strong organizational safety culture that affects the individual work behavior in high risk industries (Shappel et al, 2007). 
Safety intentions prevails in ensuring that the intended task is carried out correctly and diligently and this would prevent any errors and violations. An error is made due to lack of knowledge or discipline, whereas violation is an act of purposely breaking the rules that can attract punishment. Only in an open and just culture could we have an open reporting system and to inculcate it we need to have good safety culture. The emerging conflict between an aviation commercial organization practices may result in undue pressure to the individual professionals and may led to safety intentions that could warrant errors or violations and could led to an accident (Wiegmann and Shappell, 2003).

As our study looks at the human factor issues of the LAEs and their environment and based on our literature review a number of research study on human behaviors utilizes the theory of planned behavior. This theory looks at the three constructs of human behaviors that is the attitudes, norms and controls (Azjen,1985). As such the importance to explore this theory as to model the theory constructs of this research in fact this theory is an extension of the theory of reasoned actions. The studies on Turkish Pilots that was carried out in 2010 used the theory of planned behavior as the core theory. It focusses on four sub-components including individual attitude, management attitude, workplace pressures and group norms. The theory of planned behavior guides the study model in explaining individual variability in safety behavior through organizational safety culture (Uryan, 2010).

This is also an important behavioral theory that looks at human behavior and intentions. It is a based theory in which the theory of planned behavior evolved from. This theory was founded by Martin Fishbein together with Ajzen in 1980. It focusses on the factors that relates attitudes and behaviors that results in the action of the individual (Fishbein, 1967). As our study looks at human behavior, it is thus important to also observe at this theory as part of the research study. Part of the study includes looking at the safety climate, as a measurable criterion for safety culture in the workplace. And as the study will also look at a model proposing that the organizational safety culture does affect the individual safety intentions (Cooper and Phillips, 2004)

One of the critical work force that is involve in maintaining this safety performance is the licensed aircraft engineers which is responsible to issue the maintenance release to ensure that the aircraft is safe for the intended flight (ZRST Air leg, 2019). As such we also need to look at what motivates this group towards safety performance.

Studies on motivational items in the work process has been carried out mostly in industrialized nations, most notably the western world, in recent years due to economic and business globalization movement, makes motivational factor an important element in developing countries (Manshor and Abdullah, 2002).

Motivator needs are related to the nature of work itself and how challenging it is. Outcomes such as interesting work, autonomy, responsibility, being able to grow and develop on the job and a sense of accomplishment and achievement help to satisfy motivator needs (Jones, et al.,1998).

Earlier study (Kovach, 1980) has shown that full appreciation of work done is the most important motivational factor among industrial workers in the United States. In contrast, in 1986 the top concern was interesting work (Kovach, 1987). Studies among hotel employees in the Caribbean, 
INTERNATIONAL JOURNAL OF ACADEMIC RESEARCH IN BUSINESS AND SOCIAL SCIENCES

Vol. 10, No. 5, May, 2020, E-ISSN: 2222-6990 ㄷ 2020 HRMARS

United States and Canada have shown good wages and job security were ranked as the main motivational factors. (Charles and Marshall,1992; Simon and Enzs, 1995).

Remuneration were found to be the highest ranked among the primary motivators for both Russia and Polish employees in retail firms (Huddleston and Good, 1999). In the Malaysian context, job security is ranked as among the highest motivators for employees in the work place (Zakaria and Zaidatol, 1997). The prevailing activities of the global business environments such as mergers, acquisitions, transformations and rightsizing affected the workforce in terms of job security and wages. In such times, the basic needs may resurface as important factors (Wiley, 1995).

Job related motivational studies in Malaysian organizations are limited. The imperatives of economic development and competition require organizations to utilize and manage their human resources fully to achieve higher performance. Contribution of motivational management to organizational performance is therefore necessary (Manshor and Abdullah, 2003). As such the need for also to look at the human factor issues as given in the following models (ZRST human Factors, 2019).

Following are some examples of human factor error models used in the industry,

1. Swiss Cheese Model. (Accident causation model that is cause by flaws in defense layers)

2. PEAR Model. (People, Environment, Actions and Resources);

3. SHELL Model (Software, Hardware, Environment, Liveware (Individual), Liveware (Teams))

It can be noted that the human factor error models centered on human behavioral characteristics that effects the error modelling.

The Swiss cheese model of accident causation is now adopted as the model for investigation in many industries including aviation industry. The Swiss cheese model shows several layers between management decision making and accidents and incidents (Reason, 1990). However, overzealous implementation of a theoretical framework has led to an illusion of management responsibility for all errors. In this case we need also to consider the role of human factors, as the management also represent a group of individuals.

Human factors in aviation maintenance uses the PEAR error model as a simple framework to identify the causal factors. Four elements of the PEAR Model consist of the major elements of the causal factors that determines human errors or violations and in essence focus on the people issues as the main factor. While the "people" component is only one of four in the PEAR model, people are at the heart of the entire model. Human Factors studies concentrates and focusses on primarily with people factor and how they interact with each other and the environment around them (Zrst, 2019).

The cornerstone of HF theory is the SHELL Model. The human, or in the case of aircraft maintenance, the aircraft engineers and technicians, is the centre of this model. The cornerstone of this error model also concentrates on the people factor namely the liveware for individual and liveware for teams. It is from this model that the context of the importance of understanding the human factor element comes in and thus to be use to further understand to mitigate the errors. 
INTERNATIONAL JOURNAL OF ACADEMIC RESEARCH IN BUSINESS AND SOCIAL SCIENCES Vol. 10, No. 5, May, 2020, E-ISSN: 2222-6990 @ 2020 HRMARS

It is hoped that this study would assist to design and formulate the needed motivational values, both intrinsic and extrinsic to generate the right formula in terms of productivity, efficiency and capacity for the licensed aircraft engineers to assist to transform the Maintenance, Repair and Overhaul (MRO) industry of the Aviation industry.

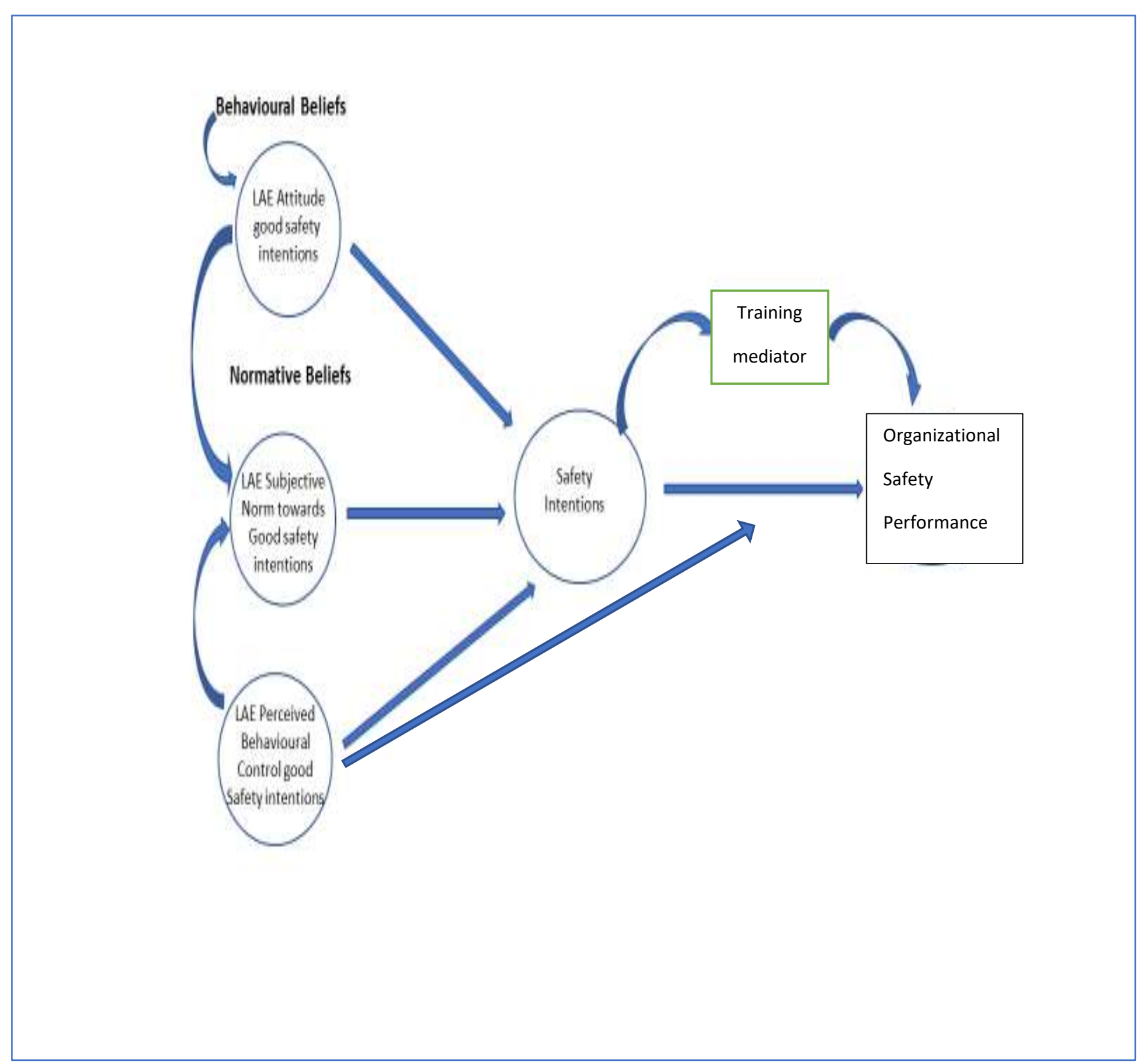

Figure 1. Underpinning Study Model (Theory of Planned Behavior) 


\section{Variables and Measurements}

This study uses the theory of planned behavior (TPB) as the underpinning theory as given in figure 1 . The Independent variables being the individual attitude, perceived behavioral controls and subjective norms being the exogenous variables as they are factors occurring outside the model (Awan, 2018). Safety intentions act as a mediator for the independent variables and organizational safety performance. Using the factor roles of training as the mediating affect for safety intention towards the organizational safety performance. It is the context of this study that analyzing the human factors determinants that affects the safety intention towards organizational safety performance could provide a positive environment by reducing error in aircraft maintenance.

\section{Limitation}

This study is at its conceptual stage and focusses only one group of licensed aircraft engineers based in Malaysia. Thus it is recommended that this study be further extended to add in empirical evidences and cover a wider range of aircraft maintenance personnel throughout the world.

\section{Significance of Study}

This study is able to significantly contribute towards improving aviation safety by enhancing existing knowledge for aviation regulators, leaders, managers, engineers and other stakeholders in the aviation industry by identifying the human factors determinants for aircraft maintenance engineers that affect the organizational safety performance. The aviation industry is ever striving to improve its safety performance as aviation is a high-risk industry that demands high safety performance (Harro, 2019). This is due to the fact that the aircraft is flying at a high speed carrying all types of passengers of different demographics and health well-being. As such safety performance is essential in the wellbeing of the aviation industry (Siddharta, 2011).

This study introduces intangible resources such as mediating and moderating variables namely organizational safety culture, training process, human factors, safety intentions and safety performance. By studying the attitudes, subjective norms and perceived behavioral control and their correlations with the mediating and moderating effect towards the engineer's safety intentions that affects safety performance, will assist in understanding the role of the human factors to eliminate maintenance errors.

Furthermore, based on previous studies, most of the studies that associated safety intentions with organizational safety performance in the aviation industry mostly looks at flight operations rather than aircraft maintenance operations. It is also important to note that apart from safety performance impact, aviation organizations could also reap other intangible benefits such as increasing personnel motivational level thus strengthening the organizational safety culture (Siddharta, 2011).

Apart from that leaders and managers of aviation organization would be aware that by improving the human factor issues that affects safety performance, it also enhances the working culture and personnel motivational level which would translate into better productivity and optimization of resources (Ayers, 2017). 
This study is also significant to the managers as this would allow them to further investigate and implement safety performance management, whether it was developed, executed with the proper enablers or otherwise (Keller, 2020; Harro, 2019; Ayers, 2017).

Finally, this research is significant due to its perspectives and focus. The aviation industry is a vital industry for the country's economy. In fact, aviation industry in a developing economy has been identified as an essential industry to spearhead the development of the country towards a developed nation (Siddharta, 2011). Overall, by focusing on safety performance on the aircraft maintenance process we are able to further enhance the safety of aviation operations. Aircraft maintenance process is a vital process towards aviation safety performance as it produces not only active safety effects but also latent safety effects. And by being focus, it permits a more credible finding because the study is conducted at a certain critical process of aviation safety (Keller, 2020; Harro, 2019).

\section{Conclusion}

This study aims at enhancing the aviation organizational safety performance by looking at the human factors determinants that affects the licensed aircraft engineer. It is specifically aimed to understand the factors that determines the licensed aircraft engineer safety intention towards aviation safety organizational performance in the aircraft maintenance process. Safety performance in the aviation industry is key as the aviation industry is categorized as a high-risk industry. And this study would be able to contribute towards increasing the aviation organization safety performance by understanding the human factors determinants that influenced the licensed aircraft engineers towards their safety intention. This study will also assist the aviation organizations to design better work environment and work processes that will motivate the Laes towards a positive safety intention. This will contribute towards a safer and sustainable aviation industry with high safety performance which in turn will provide for better economic growth.

\section{References}

Agresti, A., \& Finlay, B. (2009). Statistical Methods for the Social Sciences (4th ed.). Upper Saddle River, NJ: Prentice Hall.

Ajzen, I. (1971) From Intentions to Actions: A theory of planned behavior. (pp 10-12) Springer

Ajzen, I., \& Fishbein, M. (1977) Attitude - behavior relations : A theoretical analysis and review of empirical research. Psychological Bulletin, Vol. 84, No.5, (pp 888-918)

Ajzen, I. (1991). The theory of planned behavior. Organizational Behavior and Human Decision; Open University Press.

Ajzen, I. (2005). Attitudes, Personality and Behavior (2nd ed.). New York, NY: Open University Press

Anderson, N. R., \& West, M. A. (1998). Measuring climate for work group innovation: development and validation of the team climate inventory. Journal of Organizational Behavior.Wiley.

Babbie, E. R. (2008). The basics of social research. Belmont, CA: Thomson/Wadsworth.

Baker, R. H. (1998) - Climate Survey analysis for aviation maintenance safety - Elsevier

Baron, R. I. (2008). Measuring safety climate at an aircraft maintenance facility: Can training change attitudes? Capella University, ProQuest Dissertations Publishing.

Becker, E. A., \& Gibson, C. C. (1998) Theory of Reasoned Action: Accurate prediction of behavioral intentions for enrolling in distance education courses. Journals.sage.com

Bland, J. M., \& Altman, D. G. (1997) Cronbach's alpha. British Medical Journal. http://www.bmj.com 
INTERNATIONAL JOURNAL OF ACADEMIC RESEARCH IN BUSINESS AND SOCIAL SCIENCES

Vol. 10, No. 5, May, 2020, E-ISSN: 2222-6990 @ 2020 HRMARS

Brandt, C. J. (2000). Climate quality and climate consensus as mediators of the relationship between organizational antecedents and outcomes. Journal of applied psychology. ResearchGate.

Brickson, S. I. (2002) Organizational identity orientation: Making the link between organizational identity and organizational behavior. Harvard University

CAAM. (2016) Civil Aviation regulations. CAAM.

CAAM. (2019) Airworthiness Notices Safety management system 2101. CAAM.

Ching, C. F., \& Chen, S. C. (2012) Scale development of safety management evaluation for the airline industry. Accident Analysis \& Prevention, Volume 47, (pp177-181)

Fogarty, G. J., \& Shaw, A. (2010) Safety climate and the theory of planned behavior: towards the prediction of unsafe behavior - Elsevier

Georgiou, A. M. (2009) The effect of human factors in aviation maintenance safety. International Symposium on Aviation Psychology, (pp 232 - 237). Http://scholar .libraries.wright.edu/isap_2009/76

Graopadhye, A. K., \& Drury, C. G. (2000) Human Factors in aviation maintenance: How we got to where we are. Elsevier.

Hernandez, A. E. (2001) Organizational climate and its relationship with aviation maintenance safety - Elsevier

Hobbs, A. (2008) An overview of human factors in aviation maintenance. Skybrary

Hobbs, A., \& Williamson, A. (2003) Associations between errors and contributing factors in aircraft maintenance. Human factors: The journal of the Human Factors and Ergonomics Society. Journal.sage.com

Hofstede, G. (2009) Geert Hofstede cultural dimensions. Taylor training.com

ICAO. (ICAO) Safety management manual 9859 edition 4. ICAO

ICAO. (2019) Annual safety survey report. ICAO

Jovanic, N. (2019) Sampling analysis. Lead Quizzes.

Keller, J., Levin, D. E., \& Teo, A. (2020) Measuring Fatigue and Sleepiness in Collegiate Aviation Pilots. Commons.erau.edu

Kim, D. H. (2017) A human factors approach for aviation safety

Kinison, H. A., \& Siddiqui, T. (2012) Toward measuring safety culture in aviation maintenance, the structure of trust and professionalism - Aviation Maintenance Management. McGraw Hill

Krulak, D.C. (2004) Human factors in maintenance: impact on aircraft mishap frequency and severity - Aviation, Space and Environmental, Volume 75 (5), (pp 429-432)

Ma, J., Pendigo, M., Blackwell, L., Gildea, K., \& Holcomb, K. (2011) The line operations safety audit program: Transitioning from flight operations to maintenance. IATA

Marais, K. B., \& Robichaud, M. R. (2012) Analysis of trends in aviation maintenance risk: An empirical approach .Elsevier

Mcdonald, N., Corrigan, S., Daly, C., \& Cromie, S. (2000) Safety management system and safety culture in aircraft maintenance organization. Elsevier

Mrusek, B. M. (2020) - Outsourcing Aircraft maintenance and related safety implications. Commons.eru.edu

Musa, O., Salehuddin, S., Nadzeer, B., Che, Z., Mohd, M. A. (2019) The impact of organizational factors towards safety management system performance of the Royal Malaysian Air Force. Academy of Strategic Management Journal

National Safety Council, (2002). Injury Facts. National Safety Council, Itasca, IL. 
INTERNATIONAL JOURNAL OF ACADEMIC RESEARCH IN BUSINESS AND SOCIAL SCIENCES

Vol. 10, No. 5, May, 2020, E-ISSN: 2222-6990 @ 2020 HRMARS

Patankar, M. S., \& Taylor, J. C. (2017) Risk management and error reduction in aviation maintenance. Routledge.

Raouf, A., Duffuaa, S., \& Ben-Daya, M. (2006) Human error in maintenance : a review, Emerald.com.

Westrum, R. (1996). Human factors experts beginning to focus on organizational factors in safety. ICAO journal.

Williamson, A. (2002) Unsafe acts and unsafe outcomes in aircraft maintenance. PubMed.gov. US National Library of Medicine National Institutes of Health.

Yusof, W. F., Kian, T. S., \& Mohamed, M. T. (2013) Herzberg two factors theory on work motivation: Does it work for today's environment? Global Journal of Commerce \& Management Perspective. Global Institute of Research and Education

ZRST. (2019) Aviation legislation. (pp 10-11) Zrst.

ZRST. (2019) Human factors in aviation. (pp 15-16) Zrst. 